\title{
Hemoglobin Values in the First Six Months of Life in Exclusively Breastfed Children
}

\author{
Rosa de Fátima da Silva Vieira Marques ${ }^{1}$, José Augusto de Aguiar Carrazedo Taddei ${ }^{2}$, \\ Fabio Ancona Lopez ${ }^{2}$, Josefina Aparecida Pellegrini Braga ${ }^{2}$
}

\author{
${ }^{1}$ Department of Integral Health, State University of Pará (UEPA), Belém, Brazil; ${ }^{2}$ Department of Pediatrics, São Paulo Medical \\ School, Federal University of São Paulo (EPM/UNIFESP), São Paulo, Brazil. \\ Email: ieddat.taddei@gmail.com
}

Received November $20^{\text {th }}, 2013$; revised December $10^{\text {th }}, 2013$; accepted December $17^{\text {th }}, 2013$

Copyright (C) 2013 Rosa de Fátima da Silva Vieira Marques et al. This is an open access article distributed under the Creative Commons Attribution License, which permits unrestricted use, distribution, and reproduction in any medium, provided the original work is properly cited.

\begin{abstract}
Objective: The inexistence of publications on hemoglobin values in the first six months of life gave us the objective of describing these values, month by month in healthy, iron sufficient exclusively breastfed infants. Methods: This was a cross-sectional descriptive study in 306 infants stratified according to age from one to six months, full-term births, weighing $\geq 2500 \mathrm{~g}$, without intercurrences at birth, serum ferritin levels $\geq 10 \mathrm{ng} / \mathrm{mL}$, followed by the public health service encouraging and supporting exclusive breastfeeding. An automated counter was used for measuring hemoglobin, and serum ferritin was determined using immunoenzymatic method. Student's t-test was used to analyze differences between means, and Mann-Whitney test when distribution was non-normal. Level of statistical significance was $p<$ 0.05. Results: The hemoglobin values, according to gender, did not differ statistically in the different months; the results are presented without sample division according to gender. Hemoglobin means and standard deviations in $\mathrm{g} / \mathrm{dL}$ were: $11.7( \pm 1.6), 10.7( \pm 1.5), 10.8( \pm 1.3), 11.6( \pm 1.5), 11.7( \pm 1.7)$, and 11.8( \pm 1.6$)$, from the first to sixth month respectively. Conclusion: The hemoglobin values obtained in all the first six months of life, based on a healthy, exclusively breastfed infant population, may contribute to the reassessment of reference levels for the diagnosis of anemia in the studied age range.
\end{abstract}

Keywords: Hemoglobin; Ferritin; Infant; Exclusive Breastfeeding; Nutrition

\section{Introduction}

The prevalence of iron deficiency anemia in the world is elevated, affecting around 2 billion individuals. It is estimated that $12 \%$ of children under the age of five years in developed countries suffer, and this rate increases to $51 \%$ in developing countries [1]. In Brazil, prevalence is estimated at around $60 \%$ for children under the age of 12 months [2]. In Belém, Pará state, anemia prevalence was $55.1 \%$ and iron deficiency was $70.4 \%$ among infants [3]. The diagnosis for iron deficiency anemia in the first months of life is extremely important since it may put the child at risk for poor psychomotor and cognitive development, which may be irreversible even after treatment [4].

The World Health Organization (WHO) has only established cutoff points for anemia from the age of six months onwards [1], making anemia studies in the under- 6-month-age range difficult. Consequently, published studies are difficult to compare, since there is no consensus on the cutoff points for anemia.

The studies that assess hemoglobin in infants under the age of six months do not determine the values for each of the first six months of life, were conducted with insufficient sample sizes, including infants on different feeding regimens: exclusively breastfed, with complimentary foodstuffs enriched or not with iron, and also differing in the use of iron supplements. Many of these studies did not assess if the children in the sample had adequate iron stocks [5-8].

Therefore, facing little uniformity in the studies and the missing standard values for hemoglobin, in each of the first six months of life, in exclusively breastfed children, we proposed to determine the distribution of hemoglobin values presented by infants, from the North of 
Brazil, with full-term births weighing over $2500 \mathrm{~g}$, without intercurrences in the neonatal period and at the time of testing, had adequate iron stocks on assessment day, and who had exclusive breastfeeding as their only source of iron in the first six months of life.

\section{Methods}

Descriptive cross-sectional study for hemoglobin values in children up to the age of six months who attended the public health service that supported and encouraged exclusive breastfeeding in Belém, Pará (The Exclusive Breastfeeding Support Program-PROAME), during the period from October 2006 to December 2008. The study was preceded with approval from the Ethics Committee in Research at Sao Paulo Medical School/Federal University of Sao Paulo and by means of authorization from the Specialized Maternal-Infant-Adolescent Reference Unit in the municipality of Belém, Pará, Brazil. Informed consent form was signed by parent(s) or legal guardian prior to the study.

\subsection{Sample Size Calculation}

For sample size calculation, we used the program BioEstat 5.0, using the means and standard deviations for hemoglobin values from the pilot study. Considering beta 0.1 and $\alpha$-bilateral 0.05 , the sample size resulted in 40 infants for each age group in the study.

\subsection{Inclusion Criteria}

Inclusion criteria were: infants enrolled in PROAME, exclusively breastfed, full-term birth (gestational age between 37 and 42 weeks), weighing $>2500 \mathrm{~g}$, without morbidity or blood transfusion from birth until blood sample collection, with serum ferritin values $>10 \mathrm{ng} / \mathrm{mL}$, and normal leukogram. The mothers with a history of malaria were excluded. Local obstetric practice is to immediately clamp the umbilical cord.

\subsection{Participants}

During the data collection period (October 2006 to December 2008), 356 infants fulfilled inclusion criteria for the study. The final sample was made up of 306 infants divided into six groups and mean age, in days, was 30 days $(\mathrm{n}=58), 61$ days $(\mathrm{n}=53), 92$ days $(\mathrm{n}=52), 122(\mathrm{n}$ $=51), 153$ days $(\mathrm{n}=49)$ and 182 days $(\mathrm{n}=43)$, standard deviation was under 5 days in all groups (Figure 1).

\subsection{Laboratory Analysis}

Blood sample was collected from infants after medical examination, via peripheral vein puncture. The samples were immediately forwarded to the Foundation Laboratory at the Center for Hemotherapy and Hematology of the State of Pará-HEMOPA

(http://www.hemopa.pa.gov.br/index.htm). The hemolobin and leukogram values were obtained using the Abbott Cell-Dyn 3500 analyzer, and serum ferritin was measured using the ELFA (enzyme linked fluorescent assay) technique. A serum ferritin value above $10 \mathrm{ng} / \mathrm{ml}$ was considered as an indicator for sufficient iron stores [9].

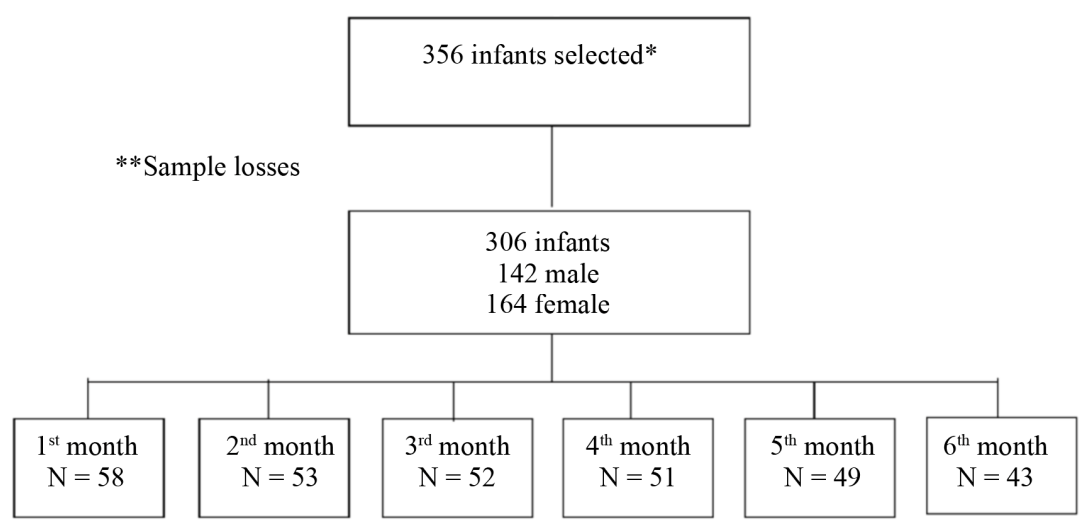

*Inclusion criteria: full-term infants, gestational age between 37 and 42 weeks, birth-weight $>2500 \mathrm{~g}$, exclusively breastfed since birth, without intercurrences in the neonatal period, healthy at the time of study, and mother without a history of malaria.

**Sample losses: 50infants $(14 \%) ; 24(6.8 \%)$ due to insufficient material for serum ferritin assessment and $26(7.2 \%)$ due to serum ferritin concentration below $10 \mathrm{ng} / \mathrm{mL}$.

Figure 1. Study flow diagram. 


\subsection{Statistical Analysis}

For the statistical analysis of data, the BioEstat 5.0 program was used. The student's t-test was used to compare means and the Mann-Whitney test when the distribution was not normal. The significance level of $p<0.05$ was adopted.

\section{Results}

Among the 306 participants of the study $46.4 \%$ were male and 53\% were female. Table 1 shows there was no statistically significant difference between the hemoglobin and serum ferritin values for the infants according to gender in the different age groups, indicating that the presentation of the results stratified by gender was not necessary.

The values and the graphical representation of hemoglobin distribution from one to six months are presented in Table 2 and Figure 2. Hemoglobin means and standard deviations in $\mathrm{g} / \mathrm{dL}$ were $11.7( \pm 1.6), 10.7( \pm 1.5)$, $10.8( \pm 1.3), 11.6( \pm 1.5), 11.7( \pm 1.7)$, and $11.8( \pm 1.6)$, from the first to sixth month, respectively, presenting homogeneous distribution in the six age groups, considering second standard deviation as cut-off to define anemia. A fall in the hemoglobin means was observed in the second and third months of life followed by recovery and stabilization in the fourth to sixth month.

Similar behaviour was found in the hemoglobin medians and the $25^{\text {th }}$ and $75^{\text {th }}$ percentiles, where lower values were presented between the second and third month and progressive elevation in the following months (Table 2).

The values and the graphical representation of ferritin distribution from one to six months are presented in Table 3 and Figure 3 . The serum ferritin means $(\mathrm{ng} / \mathrm{mL})$ were: 200 in the $1^{\text {st }}$ month, 123 in the $2^{\text {nd }}$ month, 82 in the $3^{\text {rd }}$ month, 49 in the $4^{\text {th }}$ month, 37 in the $5^{\text {th }}$ month, and 37 in the $6^{\text {th }}$ month and the medians were: 175 $\mathrm{ng} / \mathrm{mL}$ in the $1^{\text {st }}$ month, 82 in the $2^{\text {nd }}$ month, 67 in the $3^{\text {rd }}$ month, 38 in the $4^{\text {th }}$ month, 31 in the $5^{\text {th }}$ month, and 31 $\mathrm{ng} / \mathrm{mL}$ in the $6^{\text {th }}$ month (Table 3).

\section{Discussion}

From our knowledge, this is the first study to determine the hemoglobin values in the first six months of life in healthy, iron sufficient, exclusively breastfed infants, in each month.

Studies assessing the hemoglobin values in infants in the first six months of life are scarce, probably due to the fact that hemoglobin values vary greatly in this period of life. From birth, hemoglobin values suffer modification characterized by age, there is a decrease in the first weeks of life, reaching the lowest concentrations between the eighth and twelfth week, followed by gradual increase up to the age of six months [5], a similar trend was also observed in this study.

Existing studies assessing hemoglobin in the first semester of life, did not describe the values in each month, in which many did not control feeding and others did not analyse ferritin values or sample size. In this study, we tried to control all of these variables, seeking to define in this manner the normal hemoglobin values for the studied population. Hemoglobin means encountered did not present statistically significant differences in gender and age, in compliance with studies conducted by Saarinen, Siimes [5] and Brault-Dubuc et al. [6].

In this current study homogenous distributions were witnessed in the six age groups and the expected decrease between the second and third months of life was observed, recovering and stabilizing from the fourth to the sixth month [5].

Domellöf et al. [10], in studying the iron "status" of infants, in this age range, observed that hemoglobin and ferritin values were significantly lower for males, however it is important to highlight that hemoglobin values are dependent on weight in this period of life [11], and as

Table 1. Distribution of hemoglobin concentrations $(\mathrm{g} / \mathrm{dL})$ and serum ferritin $(\mathrm{ng} / \mathrm{mL})$ of infants according to age group and gender. Belém-Pará, 2006/2008.

\begin{tabular}{|c|c|c|c|c|c|c|}
\hline \multirow[b]{2}{*}{ Months } & \multicolumn{2}{|c|}{ Hemoglobin $(\mathrm{N})$ Mean \pm SD } & \multicolumn{4}{|c|}{ SerumFerritin $(N)$ Mean \pm SD } \\
\hline & Male & Female & $\mathrm{p}$ & Male & Female & $\mathrm{p}$ \\
\hline 1 & $(28) 12.0 \pm 1.4$ & $(30) 11.5 \pm 1.8$ & 0.302 & $(28) 200 \pm 149$ & $(30) 201 \pm 139$ & 0.978 \\
\hline 2 & $(22) 10.6 \pm 1.7$ & $(31) 10.8 \pm 1.4$ & 0.609 & $(22) 91 \pm 60$ & $(31) 145 \pm 159$ & $0.372^{1}$ \\
\hline 3 & $(25) 10.6 \pm 1.2$ & $(27) 10.9 \pm 1.4$ & 0.393 & $(25) 68 \pm 41$ & $(27) 95 \pm 72$ & $0.252^{1}$ \\
\hline 4 & $(28) 11.4 \pm 1.9$ & $(23) 11.8 \pm 1.4$ & 0.511 & $(28) 39 \pm 25$ & $(23) 62 \pm 46$ & $0.071^{1}$ \\
\hline 5 & $(20) 11.5 \pm 1.6$ & $(29) 11.7 \pm 1.7$ & 0.598 & $(20) 32 \pm 20$ & $(29) 41 \pm 25$ & 0.215 \\
\hline 6 & (19) $12.0 \pm 1.7$ & $(24) 11.7 \pm 1.5$ & 0.637 & $(19) 38 \pm 27$ & $(24) 36 \pm 20$ & 0.722 \\
\hline
\end{tabular}

$\mathrm{SD}=$ Standard Deviation, $\mathrm{p}$ T-test, $\mathrm{p}^{1}$ Mann-Whitney test. 


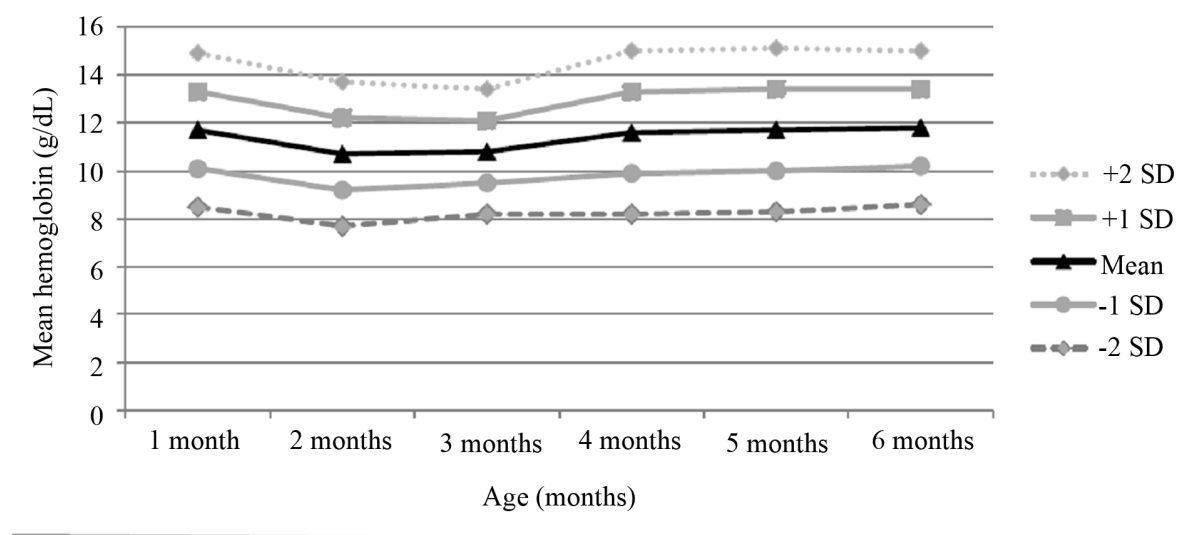

Figure 2. Mean haemoglobin concentrations and standard deviations of exclusively breastfed infants aged 1 to 6 months. Belém-Pará, 2006 to 2008.

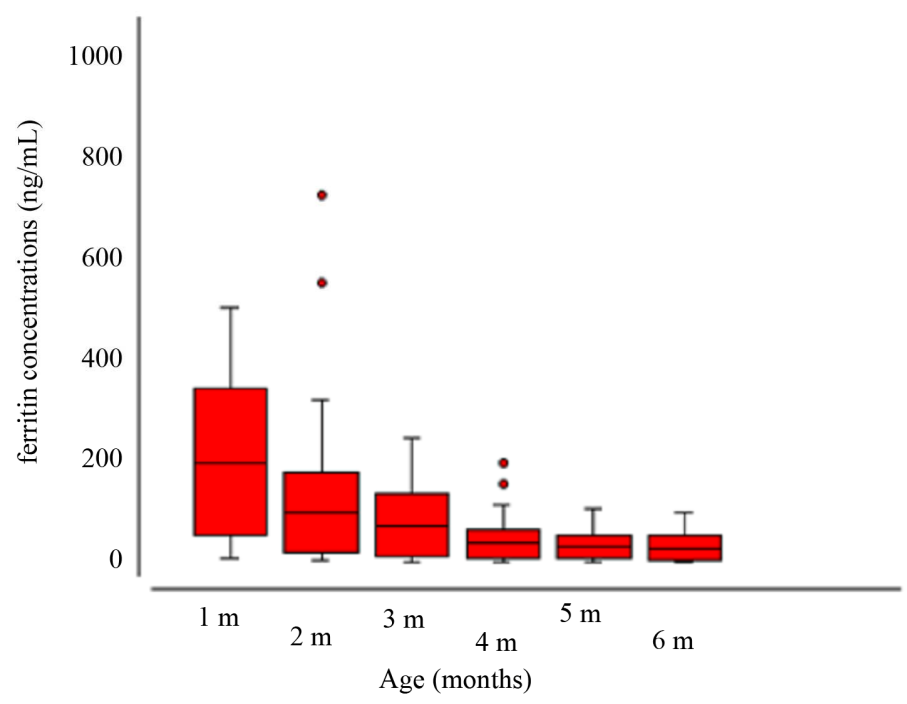

Figure 3. Mean ferritin concentrations and standard deviations of exclusively breastfed infants aged 1 to 6 months. BelémPará, 2006 to 2008.

Table 2. Distribution of values of hemoglobin $(\mathrm{g} / \mathrm{dL})$ for infants aged 1 to 6 months. Belém-Pará, 2006/2008.

\begin{tabular}{ccccccc}
\hline & \multicolumn{6}{c}{ Age in Months (N) } \\
\hline & $1(58)$ & $2(53)$ & $3(52)$ & $4(51)$ & $5(49)$ & $6(43)$ \\
$+2 \mathrm{SD}$ & 14.9 & 13.7 & 13.4 & 15.0 & 15.1 & 15.0 \\
$+1 \mathrm{SD}$ & 13.3 & 12.2 & 12.1 & 13.3 & 13.4 & 13.4 \\
Mean & 11.7 & 10.7 & 10.8 & 11.6 & 11.7 & 11.8 \\
$-1 \mathrm{SD}$ & 10.1 & 9.2 & 9.5 & 9.9 & 10.0 & 10.2 \\
$-2 \mathrm{SD}$ & 8.5 & 7.7 & 8.2 & 8.2 & 8.3 & 8.6 \\
Median & 11.7 & 10.6 & 10.7 & 11.2 & 11.6 & 12 \\
$\begin{array}{c}\text { First Quartile (25\%) } \\
\text { Third Quartile } \\
(75 \%)\end{array}$ & 10.82 & 9.64 & 9.85 & 10.55 & 10.4 & 10.65 \\
\hline
\end{tabular}

$\mathrm{SD}=$ Standard deviation . male infants present a greater growth curve than females, this factor may have influenced this difference between studies, since the authors did not control analyses for weight.

Saarinen, Siimes [5], published hematimetric absolute rates and standard limits, which have been used as reference for infants up to the age of six months. It is important to highlight that although the values obtained in this study have been used as reference in literature, this study did not conduct assessments in the third and fifth months of life. Feeding varied between the infants $(n=256)$ and during the study, the number of exclusively breastfed infants which at the beginning was high, decreased to $38 \%$ ( $4^{\text {th }}$ month of life) and $25 \%$ of infants $\left(6^{\text {th }}\right.$ month of life). Other than this, there was complementary feeding with iron-enriched infant formulas and cow's milk with home preparation. Furthermore, continuous iron supple- 
Table 3. Distribution of values and of ferritin $(\mathrm{ng} / \mathrm{mL})$ for infantsaged 1 to 6 months. Belém-Pará, 2006/2008.

\begin{tabular}{|c|c|c|c|c|c|c|}
\hline \multicolumn{7}{|c|}{ Age in months $(\mathrm{N})$} \\
\hline & $1(58)$ & $2(53)$ & $3(52)$ & $4(51)$ & $5(49)$ & $6(43)$ \\
\hline Mean (Standard Deviation) & $200(143)$ & $123(129)$ & $82(60)$ & $49(37)$ & $37(24)$ & $37(23)$ \\
\hline Minimum-Maximum & $11-507$ & $13-726$ & $12-249$ & $10-197$ & $10-107$ & $10-100$ \\
\hline Median & 175 & 82 & 67 & 38 & 31 & 31 \\
\hline First Quartile (25\%) & 83.75 & 50 & 37 & 22.5 & 20 & 19.5 \\
\hline Third Quartile (75\%) & 298.75 & 160 & 101 & 65 & 48 & 46 \\
\hline
\end{tabular}

mentation during the first year of life, varied between infants in the sample.

Hemoglobin means in the sixth month of life in our study although lower than those in the study conducted by Saarinen-Siimes [5], were similar to those found by Friel et al. [12] at $11.6 \mathrm{~g} / \mathrm{dL}$ and Dube et al. [13] and $11.8 \mathrm{~g} / \mathrm{dL}$, for the $4^{\text {th }}$ month, the last two studies were conducted with exclusively breastfed infants.

It is important to point out that many studies assessing hemoglobin in the age range we studied, presented small sample sizes [7,8], were under different feeding regimes $[5,6]$; not all of the studies analysed the iron stores of the studied infants and none of the studies, not even the one conducted by Saarinen-Siimes [5], evaluated hemoglobin in each of the first six months of life.

The differences obtained between the hemoglobin values in this study to those obtained in the study by Saarinen-Siimes [5], may also be methodological, since the study by Saarinen-Siimes [5], was performed more than three decades ago. Their comparisons used different methodologies or different apparatus that are not always considered valid, as the accuracy between different apparatus is important when dealing with comparisons.

WHO did not define values for anemia below the age of six months, generating in this manner a lot of controversy on anemia prevalence in several studies. Some authors considered infants under the age of six months being anemic who presented $\mathrm{Hb}$ values $<11 \mathrm{~g} / \mathrm{dL}$, defined by WHO [1] for infants over the age of six months, overestimating in this manner anemia prevalence for this age group.

Domellof et al. [10], in the study on diagnostic criteria for iron deficiency and iron deficiency anemia considered $\mathrm{Hb}$ concentrations below $<10.5 \mathrm{~g} / \mathrm{dL}$ for infants aged four to six months and below $<10 \mathrm{~g} / \mathrm{dL}$ for those aged nine months and concluded on the need for reassessment of diagnostic criteria for iron deficiency anemia.

In 2006, in a study published by Beutler, Waalen [14], the authors discussed WHO standards, defined four decades previously by Blanc et al. [15] and so widely used in epidemiological studies, which may contain serious flaws, due to the fact that many references were based on a relatively small number of individuals without methodological accuracy, in the manner that blood collection was performed (venous puncture or finger prick) with standards that hemoglobin concentration was measured (venous or capillary), which as consequence could cause "untrustworthy" or "incomparable" results. In this manner the authors question the cut-off points for anemia based on the advancement of laboratory diagnosis available today.

As limitations of this study, we could mention the lack of hematimetric rates that might improve the accuracy and trustworthiness of hemoglobin concentrations. Furthermore, we did not perform the C-reactive protein (CRP) test to assess the presence of inflammatory processes that may alter the serum ferritin values, nevertheless, it was in our understanding that such processes may be discarded in considering information from clinical data and leukogram. Furthermore, the lack of data on timing of umbilical cord clamping due to technical difficulties, already identified in the methodology, may have influenced results, however the exclusion of iron deficient infants at all months of the study, with adequate mean and median ferritin values, guaranteed the trustworthiness of hemoglobin concentrations.

We concluded that in the light of current knowledge, adequate methodology and sample size, criteria for sample selection, maintaining a single feeding regimen, laboratory control of iron stores, modern collection and testing techniques, having enabled the acquisition of hemoglobin values, may contribute to the reassessment of cut-off points for anemia in this age range.

\section{Acknowledgements}

We would like to the participating mothers, the team from PROAME, management from the Specialized Reference Unit for Mothers and Infants at the Public Secretariat of Health of Pará State (UREMIA-SESPA) where the study was conducted and Foundation Laboratory at the Center for Hemotherapy and Hematology of the State of Pará (HEMOPA) where the laboratory tests were per- 
formed.

\section{REFERENCES}

[1] WHO/CDC (World Health Organization/CDC Centers for Disease Control and Prevention, Atlanta), "Worldwide Prevalence of Anaemia 1993-2005. WHO Global Database on Anaemia," Geneva, 2008.

[2] M. G. N. Spinelli, D. M. L. Marchioni, J. M. P. Souza, S. B. de Souza and S. C. Szarfarc, "Fatores de Risco Para Anemia em Crianças de 6 a 12 Meses no Brasil," Revista Panamericana de Salud Pública, Vol. 17, No. 2, 2005, pp. 84-91. http://dx.doi.org/10.1590/S1020-49892005000200004

[3] M. B. P. Neves, E. M. K. Silva and M. B. Morais, "Prevalência e Fatores Associados à Deficiência de Ferro em Lactentes Atendidos em um Centro de Saúde-Escola em Belém, Pará, Brasil," Cadernos de Saúde Pública (Rio Journal), Vol. 21, No. 6, 2005, pp. 1911-1918. http://dx.doi.org/10.1590/S0102-311X2005000600041

[4] B. Lozoff, "Iron Deficiency and Child Development," Food and Nutrition Bulletin, Vol. 28, Suppl. 4, 2007, pp. 560-571.

[5] U. M. Saarinen and M. A. Siimes, "Development Changes in Red Blood Cell Counts and Indices of Infants after Exclusion of Iron Deficiency by Laboratory Criteria and Continuous Iron Supplementation," Journal of Pediatrics, Vol. 92, No. 3, 1978, pp. 412-416. http://dx.doi.org/10.1016/S0022-3476(78)80429-6

[6] M. Brault-Dubuc, M. Nadeau and J. Dickie, "Iron Status of French-Canadian Children: A Three Year Follow up Study," Human Nutrition. Applied Nutrition, Vol. 37, No. 3, 1983, pp. 210-221.

[7] B. Duncan, R. B. Schifman, J. J. Corrigan Jr. and C. Schaefer, "Iron and the Exclusively Breast-Fed Infant from Birth to Six Months," Journal of Pediatric Gastroenterology and Nutrition, Vol. 4, No. 3, 1985, pp. 421425. http://dx.doi.org/10.1097/00005176-198506000-00017

[8] E. B. Calvo, A. C. Galindo and N. B. Aspres, "Iron Status in Exclusively Breast-Fed Infants," Pediatrics, Vol. 90, No. 3, 1992, pp. 375-379.

[9] E. M. de Maeyer, "Preventing and Controlling Iron Deficiency Anaemia through Primary Health Care. A Guide for Health Administrators and Programme Managers," World Health Organization, Geneva, 1989. http://dx.doi.org/10.1002/food.19900340432

[10] M. Domellöf, K. G. Dewey, B. Lönnerdal, R. J. Cohen and O. Hernell, "The Diagnostic Criteria for Iron Deficiency in Infants Should Be Reevaluated," Journal of Nutrition, Vol. 132, No. 12, 2002, pp. 3680-3686.

[11] M. A. Torres, J. A. P. Braga, J. A. A. C. Taddei and F. J. Nobrega, "Anemia em Lactentes de Baixa Renda em Aleitamento Materno Exclusivo," Journal of Pediatrics, (Rio Journal), Vol. 82, No. 4, 2006, pp. 284-288. http://dx.doi.org/10.1590/S0021-75572006000500010

[12] J. K. Friel, K. Aziz, W. L. Andrews, S. V. Harding, M. L. Courage and R. J. Adams, "A Double-Masked, Randomized Control Trial of Iron Supplementation in Early Infancy in Healthy Term Breast-Fed Infants," Journal of Pediatrics, Vol. 143, No. 5, 2003, pp. 582-586. http://dx.doi.org/10.1067/S0022-3476(03)00301-9

[13] K. Dube, J. Schwartz, M. J. Mueller, H. Kalhoff and M. Kersting, "Iron Intake and Iron Status in Breastfed Infants during the First Year of Life," Clinical Nutrition, Vol. 29, No. 6, 2010, pp. 773-778. http://dx.doi.org/10.1016/j.clnu.2010.05.002

[14] E. Beutler and J. Waleen, "The Definition of Anemia: What Is the Lower Limit of Normal of the Blood Hemoglobin Concentration?" Blood, Vol. 107, No. 5, 2006, pp. 1747-1750. http://dx.doi.org/10.1182/blood-2005-07-3046

[15] B. Blanc, C. A. Finch and L. Hallberg, "Nutritional Anaemias. Report of a WHO Scientific Group," WHO Technical Report Series, Vol. 405, No. 1, 1968, pp. 1-40. 